\title{
Observatório de estudos em Ciência da Informação: mapas, redes, rizomas e labirintos
}

\author{
Centre for Studies in Science Information: maps, networks, rhizomes and mazes
}

\begin{abstract}
Luciana de Souza Gracioso
Doutora em Ciências da Informação pela Universidade Federal Fluminense - UFF Coordenadora do Curso de Biblioteconomia e Ciência da Informação do Departamento de Ciência da informação da Universidade Federal de São Carlos - UFSCar.

E-mail: luciana@ufscar.br
\end{abstract}

Rendón Rojas esteve no Brasil. Munido de um projeto e uma boa intenção, visitou três lócus substantivos da Ciência da informação brasileira. USP (Universidade de São Paulo), UFMG (Universidade Federal de Minas Gerais), IBICT (Instituto Brasileiro de Informação, Ciência e Tecnologia) e UNIRIO (Universidade Federal do Estado do Rio de Janeiro), a convite do Programa de Pós-Graduação em Biblioteconomia desta Universidade. Neste trajeto, Rendón se posiciona com um nativo peregrino, no sentido sugerido por Bauman (2001), motivado por uma busca, com a confiança de que algo poderá acontecer e ainda, consciente de que sua identidade poderá ser influenciada pelos desdobramentos da viagem. Nesta peregrinação, Rendón convida a comunidade brasileira para conhecer uma rede latina que vem se configurando para análise, estudo, discussão e pensamento sobre a Ciência da informação.

Com isto Rendón promove, antes da configuração da rede, a explicitação de uma aparente necessidade do campo, de conhecer-se. Esta busca de auto conhecimento, indiretamente estimulado por Rendón, se dá nos pesquisadores, professores e pensadores do campo, que por sua vez estão alocados em suas Universidades e Instituições de pesquisa, sendo que estas também exercem poderes de ordem cultural e ideológica sobre o modo como a própria Ciência da informação poderá ser vivida e pensada nas práticas de pesquisa cotidiana. Portanto Rendón, ao sugerir uma rede, sugeriu também a reflexão dos pesquisadores, sobre seus posicionamentos em relação a área, para a partir disto se reconhecerem e se localizarem na representação da rede. Esta auto análise, mesmo que dolorida, agregaria a área, a distinção e o reconhecimento dos diferentes territórios, fronteiras e políticas que a constituem e caracterizam. A partir disto sim, nos parece, as aproximação entre "nós" da rede, podem ser sugeridas.

Embora estejamos falando de uma Ciência da informação comum a toda comunidade científica que lhe constitui, seria de se pensar que esta mesma Ciência estaria sujeita as regras de 
vida compartilhadas em âmbito institucional, ou, independente disto, estaria também sujeita as escolhas epistêmicas feitas para vivenciá-la a partir de alguns referentes. Logo, diferentes Jogos de linguagem, diferentes gramáticas e diferentes usos (WITTGENSTEIN, 1953) constituiriam esta Ciência. Porém, como bem alerta Wittgenstein, todos os Jogos tem uma familiaridade. Todos os Jogos estão conectados por semelhanças de família, e isto se dá, no uso da linguagem. Não há um movimento ou posicionamento isolado que seja. Sempre haverá um gen comum, mesmo que não manifesto, a toda e qualquer configuração da Ciência da informação, independente de sua institucionalização e de sua localização geográfica. Assim, parecer ser que o que tornará possível a configuração da rede proposta por Rendón, seriam os parentescos existentes nas compreensões sobre a Ciência da informação e não a reprodução em série de uma única identidade.

Agora, é importante também, ao mesmo tempo, pensar a Ciência da Informação como um grande Jogo, identificando e estabelecendo talvez, o seu mapeamento genético, para identificar em que medida conceitos, cursos, grupos de pesquisa, se assemelham ou se distanciam, práticas se diferenciam ou se convergem. Esse mapeamento, naturalmente em rede, é o que Rendón nos convidou a fazer. E o agradecemos por isto.

Uma estratégia salutar, observada sobre o posicionamento do pesquisador, durante sua peregrinação por São Paulo, foi o do estimulo promovido por ele, da prática comunicativa, logo, do uso da linguagem. A ordem das intervenções, após a apresentação de sua palestra e de seu projeto, ficou a critério dos próprios participantes, ouvintes, que encadearam perguntas e observações articulando uma discussão rizomática (ao mesmo tempo plástica e elástica). Neste movimento, as interlocuções feitas pelos interventores tiveram como características posicionamentos centrais, tangenciais e transversais ao projeto de Rendón. Ao passo que novas observações eram lançadas, Rendón cumpria alguns papeis interessantes no jogo de linguagem que se estabelecia naquele contexto: o de nó da rede, por hora, e o de agente espistêmico distribuído (conceito apresentado pela Dra. M. Nélida G. Gomez durante sua arguição em São Paulo). Ao passo que perguntas eram proferidas pelos participantes, Rendón argumentava de modo aberto e, cumprindo grande parte dos critérios de validação comunicativa (como sugerido em Habermas, 1981), foram sendo estabelecidas ações comunicativas que, antes de atingirem um ideal de consenso, permitiram algo a priori - a manifestação das forças e dos ideais de emancipação de cada interlocutor ali presente, pois foi dada a oportunidade a todos participantes, 
de exporem seus posicionamentos frente aos propósitos de pesquisa apresentados por Rendón voltados a caracterização do objeto de estudo e principais categorias da Ciência da informação. Mesmo havendo um interesse comunicativo em se promover um consenso sobre os assuntos propostos, o lugar criado neste meio, durante este trânsito, neste espaço quântico, é que poderia se entender como o principal resultado das discussões alavancadas por Rendón.

Ficamos por aqui, no Brasil, como algumas tarefas: a primeira, de pensarmos a área, a segunda de nos posicionarmos perante área, a terceira, de compreendermos e respeitarmos os desdobramentos da área, e por fim, a de articular essas ações em uma rede compartilhada. Pontualmente, para agenciar alguns desdobramentos estruturais para a configuração da rede, criamos um Observatório de estudos em Ciência da informação on line (http://observatoriodecienciadainformacao.blogspot.com.br/2012/05/programacao-e-rede-depesquisadores-em.html). Nele, sinalizaremos interesses, compartilharemos nomes, contatos, organizaremos encontros e nos observaremos como atores da Ciência da informação. Deste ponto de rede, nos conectamos a Rendón e a sua Rede maior, já estabelecida, em um movimento de crescimento e fortalecimento de relações, continuum.

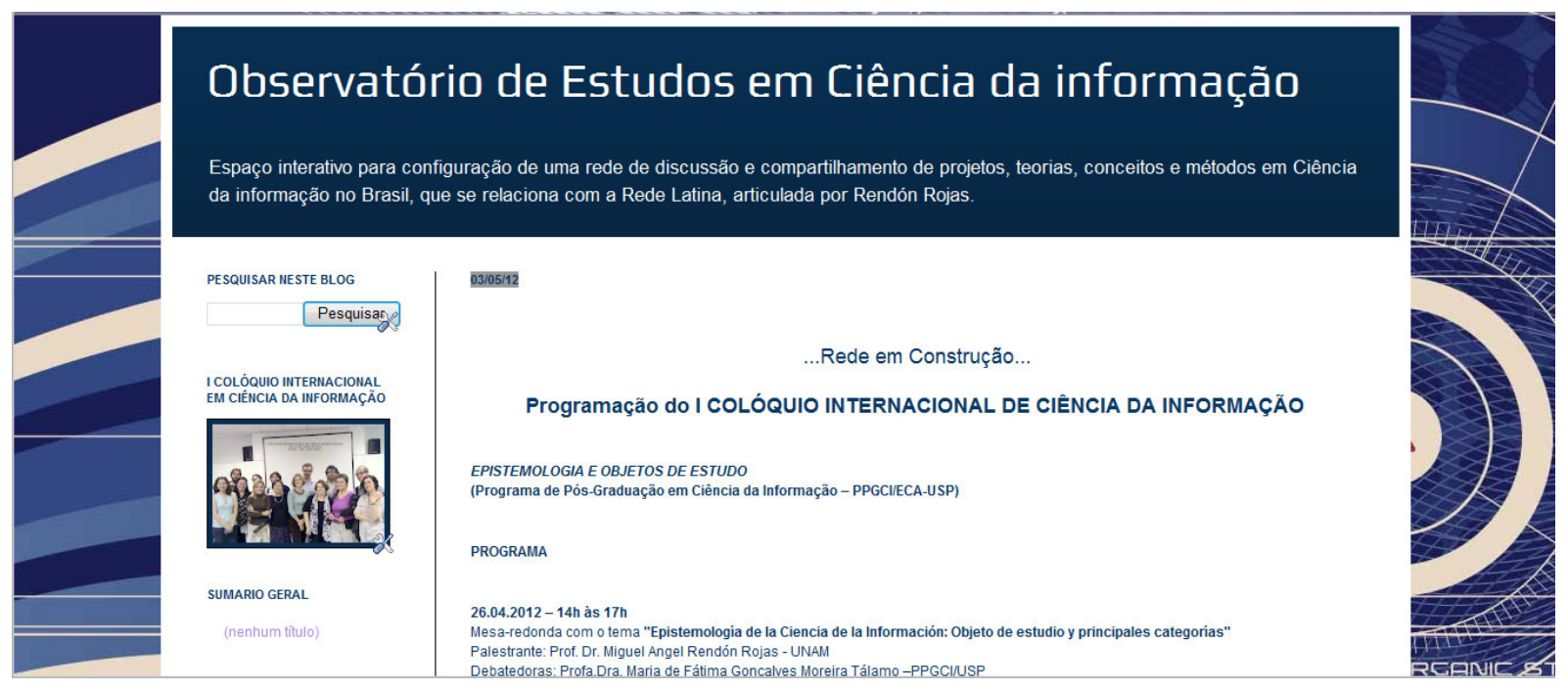

Figura 1 - Interface do Observatório de estudos em Ciência da informação, em construção. Fonte: Os autores

Este espaço virtual tem a intenção de concatenar a rede de esforços que os pesquisadores do campo da Ciência da informação têm debruçado ao estudo das categorias: Objetos, Sujeitos e Processos relacionados a este saber. Elos desta rede já haviam sido iniciados por Rendón, com 
pesquisadores brasileiros, via publicações, deste a década de 1990. Mais recentemente, os diálogos se estreitaram via Profa. Dra. Cristina Ortega (UFMG) e Profa. Dra. M. Nélida G. Gomez (IBICT) e, com participação também de Prof. Dr. Carlos, Alberto Ávila, a partir deles, outros desdobramentos da rede puderam ser pensados em âmbito nacional.

Independente de atingirmos o ideal de consenso (aquele indicado por Habermas) sobre as categorias destacadas por Rendón, caminhamos, e é neste caminhar que refazemos os trajetos, abrimos novas trilhas, interpretamos velhos mapas, criamos atalhos, desbravamos novos continentes, em um movimento quase que labiríntico, porém, motivados por um ideal intersubjetivo de conhecimento, pertencimento e potencialização do campo.

Artigo submetido em: 20 maio 2012

Artigo aceito: 20 jun. 2012

InCID: R. Ci. Inf. e Doc., Ribeirão Preto, v. 3, n.1, p. 168-171, jan./jun. 2012. 